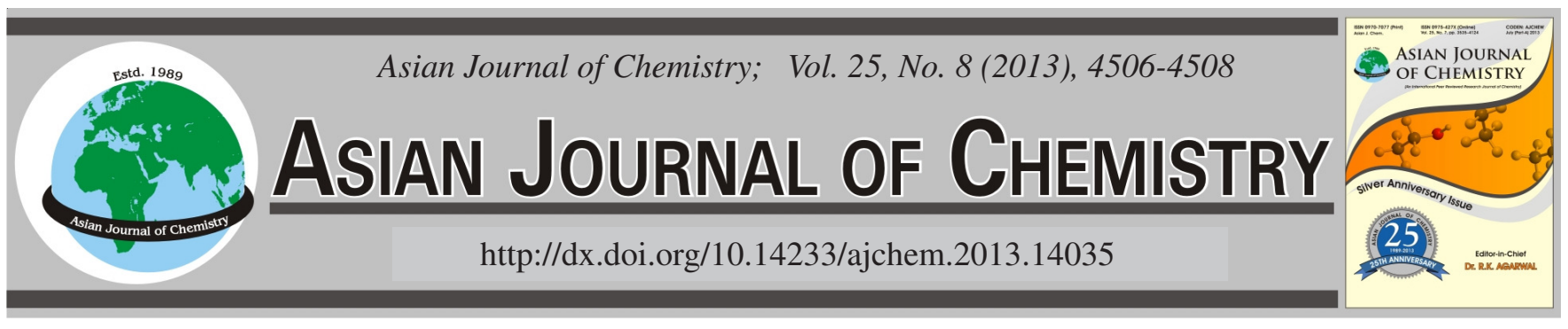

\title{
Determination of Peroxide Value in the Plastic Resin
}

Chuan Luo*, Beilei Wu, Zhenxin Lin, Lifeng Yuan and Hao Wang

Ningbo Entry-Exit Inspection and Quarantine Bureau, Mayuan Road 9\#, NingBo 315012, P.R. China

*Corresponding author: Fax: +86 574 87116346, E-mail: 1c801113@gmail.com

The peroxide value of polyethylene, polypropylene and polystyrene resin was detected by titration method, Plastic particles were dissolved in a mixed solvent of chloroform and acetic acid (2:3, volume ratio), add $0.5 \mathrm{~mL}$ of saturated potassium iodide solution, shake for exactly $1 \mathrm{~min}$ then add $30 \mathrm{~mL}$ of water, titrated with $0.01 \mathrm{~mol} \mathrm{~L}^{-1}$ sodium thiosulphate. The detection limit of the method reaches $0.05 \mathrm{mmol} \mathrm{L}^{-1}$. The relative standard deviations were below $9.5 \%$. The method was effectively applied for the determination of peroxide value in plastic particles.

Key Words: Peroxide value, Plastic resin, Polyethylene, Polypropylene, Polystyrene, Titration method.

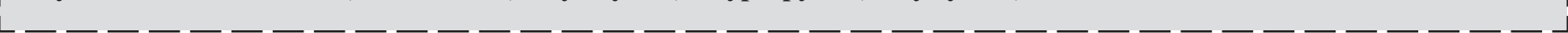

\section{INTRODUCTION}

The toxicological effects of peroxides on human bodies have received wide concern and extensive study in recent years and it can cause variation of cells and embryos that may induce biological diseases ${ }^{1-4}$. A series of test method have been established, used to detect peroxides in edible oil as well as the food and drug in China $^{5-9}$, but the detection of peroxides in the common plastics are less reported, only the German Federal Institute for risk assessment (BfR) make limited provisions for polyethylene, polypropylene and polystyrene ${ }^{10-13}$ and the test method have not been reported. Therefore, it is important that study a test method to detect the peroxide in plastics.

Refer to the test method ${ }^{5-9}$, the peroxide value $I_{p}$ is the number that expresses in milliequivalents of active oxygen the quantity of peroxide contained in $1000 \mathrm{~g}$ of the substance.

\section{EXPERIMENTAL}

All reagents were of analytical-reagent grade or higher. Ultrapure water used throughout the experiment was obtained from a Milli-Q waterpurification system of Millipore (Bedford, MA, USA). The chloroform/acetic acid mixed solution of chloroform (Sinopharm Group Co. Ltd., Shanghai, China) and acetic acid (Sinopharm Group Co. Ltd., Shanghai, China) in according with the volume ratio of 2:3 mixtures. The saturated potassium iodide solution, a saturated solution of potassium iodide (Sinopharm Group Co. Ltd., Shanghai, China) in carbon dioxide-free water, it contains some undissolved crystals, store protected from light and discard if it fails to comply with the following test. $0.01 \mathrm{~mol} \mathrm{~L}^{-1}$ sodium thiosulphate solutions were obtained by dilution of the $0.1 \mathrm{~mol} \mathrm{~L}^{-1}$ sodium thiosulphate solutions just before use. Starch solution, triturate $1.0 \mathrm{~g}$ of soluble starch with $5 \mathrm{~mL}$ of water and add, stirring continuously, to $100 \mathrm{~mL}$ of boiling water containing $10 \mathrm{mg}$ of mercury (ii) iodide. Flask fitted with a ground-glass stopper, burette, measuring cylinder etc. laboratory glass apparatus.

Analytical procedures: Accurately weight $5 \mathrm{~g}$ samples, double sample, accurate to $0.1 \mathrm{mg}$, place the sample in a 250 $\mathrm{mL}$ conical flask fitted with a ground-glass stopper. Add 30 $\mathrm{mL}$ of the mixed solution. Shake for exactly $1 \mathrm{~min}$ then add $30 \mathrm{~mL}$ of water. Titrate with $0.01 \mathrm{~mol} \mathrm{~L}^{-1}$ sodium thiosulphate, adding the titrant slowly with continuous vigorous shaking, until the yellow colour is almost discharged. Add $5 \mathrm{~mL}$ of starch solution and continue the titration, shaking vigorously, until the colour is discharged $\left(\mathrm{n}_{1} \mathrm{~mL}\right.$ of $0.01 \mathrm{~mol} \mathrm{~L}^{-1}$ sodium thiosulphate).

Carry out a blank test under the same conditions $\left(\mathrm{n}_{2} \mathrm{~mL}\right.$ of $0.01 \mathrm{~mol} \mathrm{~L}^{-1}$ sodium thiosulphate). The volume of $0.01 \mathrm{~mol}$ $\mathrm{L}^{-1}$ sodium thiosulphate used in the blank titration must not exceed $0.1 \mathrm{~mL}$.

$$
I_{p}=\frac{1000 \times c \times\left(n_{1}-n_{2}\right)}{2 \times m}
$$

where $\mathrm{I}_{\mathrm{p}}$ : peroxide value, $\mathrm{mmol} \mathrm{\textrm {kg } ^ { - 1 }}$; $\mathrm{c}$ : concentration of sodium thiosulphate solution, $\mathrm{mol} \mathrm{L}^{-1} ; \mathrm{n}_{1}$ : sample consumption volume of sodium thiosulphate solution, $\mathrm{mL} ; \mathrm{n}_{2}$ : blank test consumption volume of sodium thiosulphate solution, $\mathrm{mL} ; \mathrm{m}$ : sample weight, g. 


\begin{tabular}{lccccc}
\hline \multicolumn{5}{c}{ TABLE-1 } \\
\multicolumn{5}{c}{ SELECT OF SAMPLE WEIGHT } \\
\hline Sample weight $(\mathrm{g})$ & 0.1 & 1.0 & 2.0 & 5.0 & 10.0 \\
Sample consume $(\mathrm{mL})$ & 0.07 & 0.48 & 0.98 & 2.52 & 4.96 \\
Peroxide value $\left(\mathrm{mmol} \mathrm{kg}{ }^{-1}\right)$ & 3.50 & 2.40 & 2.45 & 2.52 & 2.48 \\
Remark & The colour is not obvious & Lighter colour & Normal & Normal & Failure \\
\hline
\end{tabular}

TABLE-2

\begin{tabular}{lccccc}
\multicolumn{5}{c}{ TABLE-2 } \\
& \multicolumn{5}{c}{ SELECT OF SOLVENT } \\
\hline Solvent & Acetone & Chloroform & Ethyl acetate & Toluene & Isooctane \\
\hline Sample consume, $\mathrm{mL}$ & $/$ & 2.43 & 1.54 & 2.26 & $/$ \\
Blank consume, $\mathrm{mL}$ & $/$ & 0.08 & 0.42 & 1.12 & $/$ \\
Peroxide value, $\mathrm{mmol} \mathrm{kg}{ }^{-1}$ & $/$ & 2.35 & 1.12 & 1.14 & $/$ \\
Remark & No colour change & Light yellow & Bright yellow & Bright yellow & No colour change \\
\hline
\end{tabular}

\section{RESULTS AND DISCUSSION}

Sample preparation and select of sample weight: Exposure to oxygen is a necessary condition for the hydrogen oxidation reaction occurs, peroxide group can only be at the surface of the plastic particles, the polyethylene and polypropylene are relatively insoluble in common solvents, therefore, solvent extraction and other extraction method are helpless. The samples were broken easily lead to unnecessary oxidation process because of polyethylene and polypropylene vulnerable to stress shear to produce the low-temperature degradation, test the plastic particles directly. Plastic peroxides and hydrogen iodide by the reaction of iodine titration of excess iodine with sodium thiosulphate standard solution, peroxide value by computing the plastic, the reaction is as follows:<smiles>[R]COOCCCC</smiles>

$\mathrm{I}_{2}+2 \mathrm{Na}_{2} \mathrm{~S}_{2} \mathrm{O}_{3} \rightarrow 2 \mathrm{NaI}+\mathrm{Na}_{2} \mathrm{~S}_{4} \mathrm{O}_{6}$

Select a different amount of sample tested, $0.01 \mathrm{~mol} \mathrm{~L}^{-1}$ sodium thiosulphate solutions used as the titration and the results in the following Table-1.

Amount of sample weight is 0.1 and $1.0 \mathrm{~g}$, the colour change is not obvious, the titration en point is difficult to judge; when sample weight is $10 \mathrm{~g}$, this has led inaccurate test that $30 \mathrm{~mL}$ mixed solvent is difficult to full immersion all the sample; when the sample weight is $5 \mathrm{~g}$, consume the amount of sodium thiosulphate solution for $2 \mathrm{~mL}$ about, in the upper part of the burette, it is easier to read, so select $5 \mathrm{~g}$ sample weight as a standard.

Select of solvent: GB/T 5538-2005 use of mixed solvent is isooctane/acetic acid mixture and other test method used are chloroform/acetic acid mixed solvent, it is necessary select an effective mixed solvent. Acetic acid in mixed solvent is to provide a slightly acidic $\mathrm{pH}$ of the environment and the provision of $\mathrm{H}$ ions with $\mathrm{KI}$ produced by reacting hydrogen iodide, chloroform or isooctane is used to dissolve the reactants. Therefore, we select acetone, chloroform, ethyl acetate, toluene, isooctane as the solvent mixed with acetic acid dissolved reactants tested, test results in the Table-2.

Acetone and isooctane by adding a saturated KI solution colour doesn't change that cannot be caused by hydrogen peroxides in the plastic with KI reaction, chloroform, ethyl acetate and toluene are able to react, but according to the results, ethyl acetate and toluene are not effective to dissolve the sample of reactive oxygen species. Therefore chosen to chloroform mixed with acetic acid as solvent.

Reaction time: Adding potassium iodide after the placement of time must be strictly in accordance with the method of the provisions of $1 \mathrm{~min} \pm 10 \mathrm{~s}$ to operate. Too long or too short will have an impact on results, not only the hydrogen peroxide oxidation of potassium iodide and oxygen in the air will also react with potassium iodide, the reaction time is too long will make the results to large. The reaction time is too short, hydrogen peroxide and potassium iodide reaction is incomplete, the result small. Sample and blank storage time should be consistent, can be timed with a stopwatch, accurate operation, to reduce systematic error and wait for a different time and then titrate added potassium iodide, the results shown in Fig. 1.

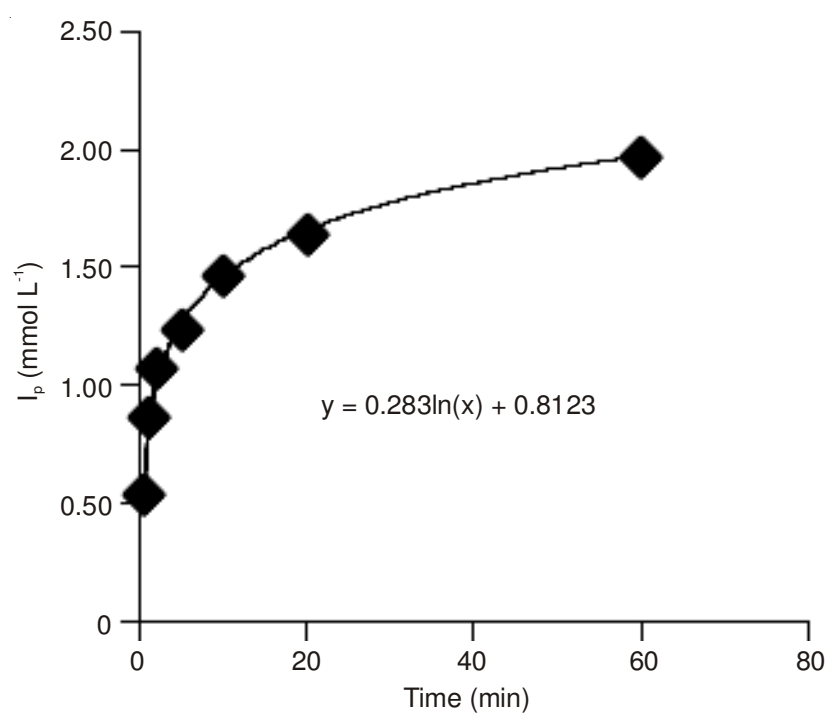

Fig. 1. Effect of the reaction time to the peroxide value

From $0.5 \mathrm{~min}$ to $60 \mathrm{~min}$ reaction time, reaction time is longer, the greater the peroxide value, But a short time is not conducive to the titration and operation, so it should be in accordance with the standards recommended by the $1 \mathrm{~min}$ time.

Select the amount of added water: A certain amount of water is added before the titration is because of the titration process requiring a higher $\mathrm{pH}$ in the system, a mixed solvent of acetic acid is first and foremost local potassium iodide reaction: 


$$
\begin{gathered}
\mathrm{CH}_{3} \mathrm{COOH}+\mathrm{KI} \longrightarrow \mathrm{CH}_{3} \mathrm{COOK}+\mathrm{HI} \\
\mathrm{RCH}_{2} \mathrm{OOH}+2 \mathrm{HI} \longrightarrow \mathrm{RCH}_{2} \mathrm{OH}+\mathrm{I}_{2}+\mathrm{H}_{2} \mathrm{O}
\end{gathered}
$$

However, in the acid environment, thiosulphate decomposed:

$$
\mathrm{S}_{2} \mathrm{O}_{3}^{2-}+2 \mathrm{H}^{+} \longrightarrow \mathrm{S} \downarrow+\mathrm{SO}_{2} \uparrow+\mathrm{H}_{2} \mathrm{O}
$$

If there is the presence of oxygen environment, the iodine anion will be oxidized by oxygen:

$$
\mathrm{O}_{2}+4 \mathrm{I}^{-}+4 \mathrm{H}^{+} \longrightarrow 2 \mathrm{I}_{2}+2 \mathrm{H}_{2} \mathrm{O}
$$

Side reaction under acidic conditions will cause the result is larger and more than hydrogen ions in the reaction, the hydrogen ions concentration increases the response to the positive direction, making the results is too large.

But in an alkaline environment, the following two side reactions will occur:

$$
\begin{gathered}
\mathrm{S}_{2} \mathrm{O}_{3}^{2-}+4 \mathrm{I}_{2}+10 \mathrm{OH}^{-} \longrightarrow 2 \mathrm{SO}_{4}^{2-}+8 \mathrm{I}^{-}+5 \mathrm{H}_{2} \mathrm{O} \\
3 \mathrm{I}_{2}+6 \mathrm{OH}^{-} \longrightarrow 5 \mathrm{I}^{-}+\mathrm{IO}_{3}^{-}+3 \mathrm{H}_{2} \mathrm{O}
\end{gathered}
$$

More than two side reactions will cause the result is small.

Summing up the analysis above, with the increase in hydrogen ion concentration in the reaction system, the oxidation of hydrogen peroxide enhancement, dissolved oxygen in the oxidation of iodide anion to the role of side reactions of iodine increases, the decomposition is also enhanced, will cause the test results increase. Therefore, before the titration, amount of water need to be add to dilute the concentration of hydrogen ions, the results shown in Fig. 2. Amount of water was added $5 \mathrm{~mL}$ to $100 \mathrm{~mL}$, with water increase in the amount of peroxide value decrease, too little water will cause a high concentration of hydrogen ions in the system, the results on the high side, so select the other test method recommended $30 \mathrm{~mL}$ water as the standard amount.

Sensitivity: The method detection limit calculated by the minimum amount of titrant, one drop $(0.05 \mathrm{~mL})$, that able to produce the colour reaction, The detection limit of the method was $0.05 \mathrm{mmol} \mathrm{L}^{-1}$.

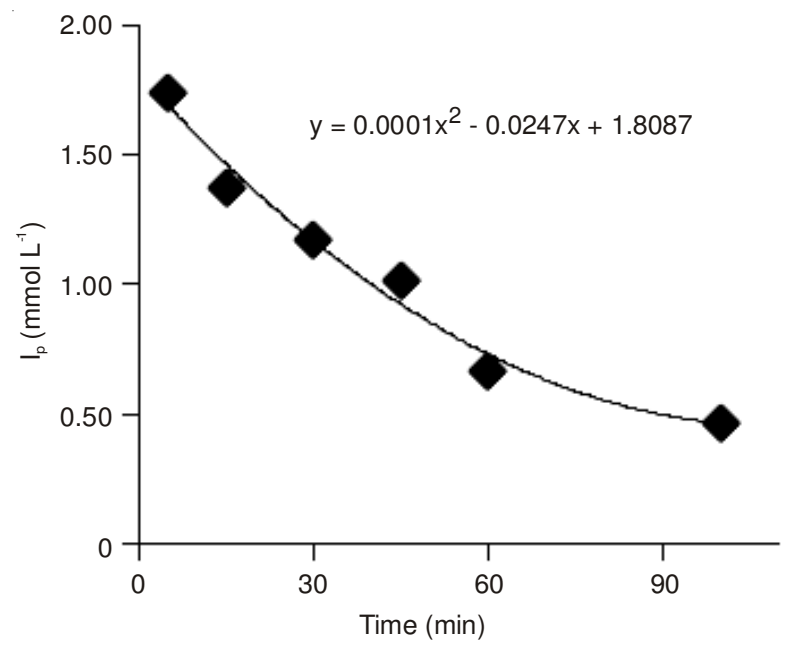

Fig. 2. Effect of amount of added water to the peroxide value
Sample analysis: The proposed method has been applied to the determination of peroxide value in the imported plastic resin. The analytical results are shown in Table-3.

\begin{tabular}{lccc}
\multicolumn{4}{c}{ TABLE-3 } \\
\multicolumn{4}{c}{$\begin{array}{c}\text { RESULTS OF PEROXIDE VALUE OF THE } \\
\text { IMPORTED PLASTIC PARTICLES }\end{array}$} \\
\hline Sample & Trademark & Result & RSD \% $(\mathrm{n}=7)$ \\
\hline Polyethylene & 5502 & 0.14 & 5.5 \\
Polypropylene & $4017 \mathrm{M}$ & 0.15 & 5.6 \\
Polystyrene & $158 \mathrm{~K}$ & 0.39 & 8.2 \\
Polystyrene & MW-1-H321 & 0.26 & 9.5 \\
\hline
\end{tabular}

The peroxide value in imported polyethylene and polypropylene resin were found to range from 0.06 to $0.20 \mathrm{mmol}$ $\mathrm{L}^{-1}$, the peroxide value of polystyrene was found to range from 0.12 to $1.12 \mathrm{mmol} \mathrm{L}^{-1}$. But the peroxide value of polyethylene, polypropylene and polystyrene may not be detected in the BfR limit provisions. This situation may be due to the polymer after mechanical shear granulation process, resulting in a molecular strand breaks to generate free radicals, generated free radicals react with oxygen in the air to product peroxide $\operatorname{group}^{14,15}$.

\section{ACKNOWLEDGEMENTS}

This work was financially supported by Ningbo Entry-Exit Inspection and Quarantine Bureau (Fund No.: 2008IK057).

\section{REFERENCES}

1. R.J. Wang and B.T. Nixon, Biomed. Life Sci., 14, 715 (1978).

2. J.A. Imlay, S.M. Chin and S. Linn, Science, 240, 640 (1988).

3. B. Halliwell, M.V. Clement and L.H. Long, FEBS Lett., 486, 10 (2000).

4. J.W. Catt and M. Henman, Human Reprod., 15, 199 (2000).

5. National Standards of People's Republic of China, GB/T 5538 (2005).

6. National Standards of People's Republic of China, GB/T 5009.37 (2003).

7. Industry Standard of the Inspection and Quarantine, SN/T 0801.3 (1999).

8. Chinese Pharmacopoeia, Method H (2010).

9. European Pharmacopoeia, Method 2.5.5 A.

10. BfR Bundesinstitut für Risikobewertung III, Polyethylen, [Stand vom 01.06.2007].

11. BfR Bundesinstitut für Risikobewertung VII, Polypropylen, [Stand vom 01.06.2007].

12. BfR Bundesinstitut für Risikobewertung V, Polystyrol, das ausschließlich durch Polymerisation von Styrol gewonnen wird, [Stand vom 01.01.2010]

13. BfR Bundesinstitut für Risikobewertung VI. Styrol-Misch und Pfropfpolymerisate und Mischungen von Polystyrol mit Polymerisaten, [Stand vom 01.04.2006].

14. R. Irinislimane, N.B.-Bensemra and A. Benlefki, J. Polym. Environ., 15, 119 (2007).

15. E.M. Hoàng, N.S. Allen and C.M. Liauw, Polym. Degrad. Stab., 91, 1363 (2006). 